\title{
THE EFFECT OF NEW TRENDS OF THE WORKING ENVIRONMENT ON WORKPLACE RISK AND ITS MODELLING
}

\author{
Antonis Targoutzidis, Hellenic Institute for Occupational Health and Safety \\ (ELINYAE), targoutzidis@elinyae.gr
}

Prof. Pavlos Karakoltsidis, Alexander Technological Educational Institute of Thessaloniki, karakol@teithe.gr

\begin{abstract}
The acceleration of global competition has brought very important changes in the working environment. Some of these changes, such as increasing part-time, temporary or self- employment (either virtual or true), intensification of labour productivity, etc. have a significant impact on workplace risk.

This impact is multilateral and complex, since the changes affect a number of different features and factors of workplace and its risks. This paper aims to identify and sort these changes in three categories (changes in production patterns and tools, changes in size of workplace and changes in employment patterns) and to explore their impact in workplace through their impact in riskaffecting factors (greater complexity in the workplace, greater potential for risky behaviour and more drivers of unconscious undesired behaviour).

The main conclusion is that the approach to risk modelling has to change taking individual-level factors and individual economic motives more explicitly into account.
\end{abstract}

Key Words: New work environment, safety, risk assessment

\section{INTRODUCTION}

Globalisation of competition has undoubtedly been the most important economic process of the 90's, with fast, wide and deep results that changed the status and the direction of development settled since the end of the Second World War (WWII) in many areas of the economy and the society, such as in 
labour, where changes are radical in the work environment, thus directly affecting Occupational Health and Safety (OHS).

The after WWII model of employment in most industrialised countries involved full-time and long-term (or even lifetime) employment with a direct contract subject to collective bargaining. Domestic labour markets were increasingly regulated with a continuous trend for reduction in working hours, as a result of the bargaining power of trade unions and limitations in labour and capital mobility. Large state-owned companies were dominating services and sectors of heavy infrastructure, whereas domination of economies of scale was maintaining and empowering commercial private giants.

Only few of these characteristics can be found in contemporary labour market. Large state-owned companies are privatising or led to free competition, which results to serious downsizing and massive personnel cuts. The same happens to many private giants. Organisations that do not change are facing serious threats, especially in the context of the current global recession. Changes are mainly about intensification of the utilisation of resources (flexibility) and incorporation of new technologies. Developments in macroeconomic context and increase of the number of Small and Medium Enterprises (SME's) completes the picture of the new labour environment.

When labour changes, the study of the workplace and the process of assessing its risks must also follow. The aim of this paper is to identify the new needs for workplace risk assessment and to propose the guidelines of an approach to meet these needs. A short analysis of the contemporary labour environment will be attempted based on existing literature, in order to produce a global picture that will allow for identification of current needs for occupational risk assessment. Causal relationships are not attempted to be proved, since this would be out of the scope of this paper.

\section{THE NEW WORKING ENVIRONMENT}

Subsequently, the main factors of the new working environment and their impact will be examined.

\subsection{Flexibility of employment}

The necessity for flexibility of resources in order to maximise their utilisation, also applies to human resources, especially for enterprises in developed countries, where labour cost is high. This utilisation is maximised when labour is employed only when required (temporary employment, part-time employment, employment via agencies) so as to reduce its volume, and by introducing competition to the providers of labour (self-employment, individual motives, labour mobility), so as to reduce its marginal cost (Mayhew et al. 1997). Both of these targets are served through labour flexibility. 
Precarious employment saw a significant increase during last decade (EUROSTAT, 2008). Projections are that a quarter of the workforce could be working in non-traditional employment arrangements by the year 2020 (Sauter and Rosenstock, 2000), whereas already by 2000 more than a quarter of all employees in the EU worked less than 25 hours per week.

The European Agency for Safety and Health at Work (OSHA, 2002a, b, c \& d) has made some efforts to explore and discuss the implications of these new forms of employment in OHS. In general, there is evidence that accident risk is systematically higher for temporary employees (Guadalupe, 2003; OSHA, 2002a, c \& d) and self-employed persons (OSHA, 2002a).

"Flexible" workers are usually assigned with more risky tasks (OSHA, 2002a; Mayhew et al. 1997), they do not have equal opportunities to safety information (OSHA, 2002a), training (Guadalupe, 2003; OSHA, 2002a \& b) or protection (OSHA, 2002c) and have less control on their work and its risks (Mayhew, Quinlan and Ferris, 1997; OSHA, 2002a).

Flexible work patterns may be seen either as a source of success and security or as a threat (James, 2000). On the one hand, pressure from the perceived threat in employment may lead to increased stress, which is positively related to risk and error proneness (OSHA, 2002a; Guadalupe, 2003) as employees are working under more pressure.

On the other hand, even as a perceived source of success, they might also lead to risky behaviour. There are studies indicating an increase to accident rate when job turns to piece-rate payment (Organisation for Economic Co-operation and Development - OECD, 1989). A number of studies (quoted in Mayhew, Quinlan and Ferris, 1997) indicate the same effect for "incentive payment" bonuses.

Labour mobility is one of the main ideas of globalisation. Workers are transferred between countries and enterprises in order to increase the utilisation of the labour resource. Thus, work organisations may have to adapt to accommodate people from different backgrounds (OSHA, 2002b), which increases the complexity of the workplace system.

Mobility also results to an increase of staff turnover and decrease of mutual commitment between the employer and the employee. This diminished commitment reduces the long term prospects and leads to behaviours with a limited time horizon, thus increasing individualism and job insecurity that might in turn lead to risky behaviour.

\subsection{Technology and flexibility in production}

New economic trends and technologies had a large impact on OHS, which has been either positive or negative in different aspects. An important trend in 
developed countries was a shift of employment from the secondary to the less hazardous tertiary sector (Organisation for Economic Co-operation and Development - OECD, 1989). Higher safety standards of modern equipment and automation have also been positive influences for workplace safety.

On the other hand, these changes in working patterns and environment, also had a negative effect on OHS. Maximisation of the utilisation of material resources and competitiveness, led to a necessity for flexibility in production (e.g. small customised bundles instead of massive production), which leads to more complexity in tasks (e.g. frequent set-ups, new sub-tasks, etc.). Contemporary industrial work seems to require less physical effort from workers, but work intensity is increasing (Harrisson and Legendre, 2003) and workers are required to be more flexible (OSHA, 2002b). Respectively, direct physical risks have been replaced by new risks, such as musculoskeletal diseases, eye fatigue, etc.

New production management trends (like J.I.T., M.R.P. or E.R.P. systems, etc.) eliminate unproductive time, thus increasing the amount and complexity of workload (Harrisson and Legendre, 2003; OSHA, 2002b). The worker is no longer hidden in the anonymity of a long, complex and massively manned production line, but closely monitored and assessed, to maximise productivity. Elimination of intermediate buffers and contingencies also increases stress. These changes might lead to exhaust and frustration of workers (Launis and Phhlaja, 2007) and increase risk (OSHA, 2002b). Moreover, the process of continuous change in modern management has been identified as a contributing factor to major accidents, stress and precarious employment (OSHA, 2002b)

However, even the impact of the positive sides of technology on safety is questioned in literature. Employment in the tertiary sector involves negative factors for OHS, such as more SME's and flexible employment, tele-working, less developed OHS systems and stressful dealing with public (OSHA, 2002c). Additionally, the effect of new safe technology in a company with a poor OHS performance is also doubtful (Harrisson and Legendre, 2003). Although new equipment includes more advanced safety systems, it is more complex and, therefore, less controllable by the worker (Leveson, 2004), thus more prone to latent failures.

\subsection{Changes in size of operational units}

As already discussed, besides the increase of size (by means of equity) of some global enterprises, the trends were downwards for operational size. There is also a general trend for increase of small enterprises (OSHA, 2002b). More analytically Between 1988-2003, the number of and employment in micro enterprises saw a significant increase (European Network for SME Research, 2004). 
A wide literature (quoted in Sorensen, Hasle and Bach, 2007 and Dorman, 2000) indicates an increased accident risk and incidence rates (OSHA, 2001; Clifton, 2005) in small enterprises, especially when it comes to serious injuries. Micro firms may expect a short life-span with an average of 5 years (Clifton, 2005). The risk for employees of new companies appears to be higher than the risk for older enterprises (OSHA, 2002c). Moreover, since the benefits (and the respective economic returns) of investment in $\mathrm{OHS}$ are in the long term, it is unlike that a small company with uncertain future will ever undertake it.

Additionally, small enterprises have less formal management, lack of resources (OSHA, 2001), little knowledge on OHS and experience in accidents, limited training and organisation in OHS, difficult access to OHS services, rare inspections, etc. (Biggins, 1996)

Apart from the increase in small enterprises, operational units of large enterprises also operate as small enterprises, i.e. as semi-autonomous units (OSHA, 2002b), for flexibility reasons. Downsizing and outsourcing are very common approaches in modern management, in order to achieve similar flexibility and controllability with small enterprises.

Structures of autonomous business units lose their central safety department, whereas their resources are inadequate to support such an operation in unit level (Duffield, 1999). Studies in Finland and the USA also point to increased sick-leave absence, trauma, and musculo-skeletal and stress-related disorders among the "survivors" of downsizing (Clifton, 2005). In general, there are numerous studies (cited in OSHA, 2002a) indicating the negative effects of restructuring and downsizing on OHS. Quoting Sorensen, Hasle and Bach (2007) "... large enterprises centralised power and decentralised work. In many cases this leads to poor working conditions in small sweatshops."

\subsection{Changes in macroeconomic environment}

The global macroeconomic environment has also changed significantly, due to the impact of globalisation or other phenomena, such as demographic factors. The percentage of ageing and female workers is continuously rising (Clifton, 2005; EUROSTAT 2008). These categories of workers have different needs and risk characteristics (OSHA, 2002b\&c; Salminen, 2004).

One of the main victims of labour mobility was unionisation, which has decreased across EU and it is lower in SME's (OSHA, 2002b), in precarious workers and in decentralised (Mayhew, Quinlan and Ferris, 1997).

Decrease of unionisation is related to respective decrease of collectiveness in workplaces, bargaining power and job security. Moreover, it appears to be connected to higher accident rates and lower worker consultation on safety issues (OSHA, 2002b). 
Globalisation of competition inevitably bounds the potential of governmental intervention, which is restricted to OHS law enforcement and incentives (mainly through insurance). EU OHS legislation has already been criticised for incapacity to correspond to the new working environment and to ensure a common level of workplace standards in all countries (Walters, 1996). The intensification of global competition has led countries in a competition to attract capital investments, which makes any further economic burden (such as costs for higher workplace standards or intensification of law enforcement) hard to apply (Dorman, 2000; Ettiene, 1996). On the contrary, deregulation of labour and social security system is rapidly adopted.

Of course there is no evidence that any country or company in the long term would benefit from a low level of safety and health (OECD, 1989). However, competition usually sets the focus on short term results that may even lead to a situation of "prisoner's dilemma".

\section{REQUIREMENTS FOR MODERN WORKPLACE RISK ASSESSMENT}

The analysis of previous paragraphs indicates that there is a complex situation that defines a new working environment that is substantially different from the traditional Tayloristic paradigm ant this difference has very serious implications for workplace safety.

A global (but not exclusive) picture of the new working environment concerning OHS appears in Figure 1.

Figure 1. The context of new working environment

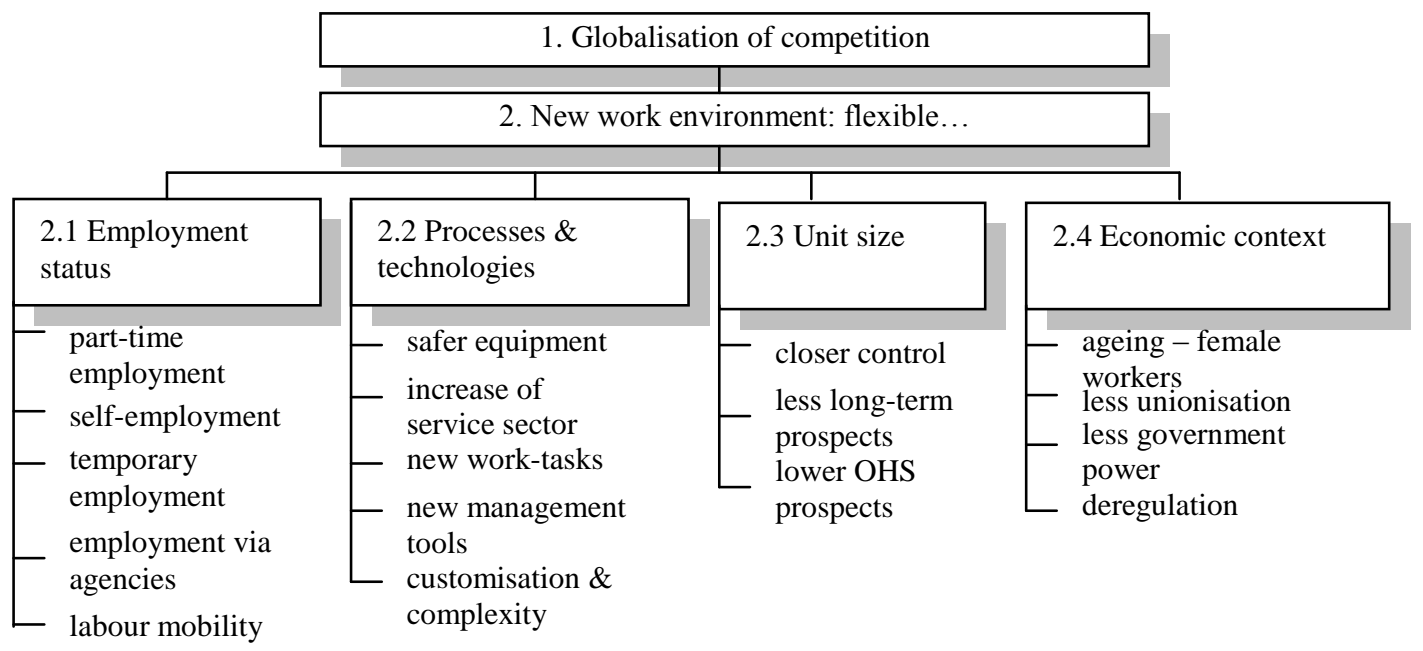


Since such important changes have taken place in working environment, the model for its representation to the process of identification and assessment of risks must also be updated. A new model is required to help representing the new situation in workplaces. In order to define the guidelines of such a model, the main implications of the main features of the new working environment have to be highlighted.

Flexibility of employment has three main implications:

$>$ Changes in the motivation of the employee: workers are either paid on a piece-rate (self-employed) or under insecure employment. Both of them give a strong motive to the employee to maximise profits or to pursue a more permanent contract. These motives add weight to productivity compared to safety, urging for higher productivity even at the cost of safety, i.e. to potential intentional risky behaviour. There are numerous studies (cited in OSHA, 2002d) supporting a positive relation between precarious employment and risky behaviour.

$>$ Stress: pursue of higher productivity standards, along with insecurity for the present situation adds to stress, which is recognised in human error literature as a key factor for erroneous (i.e. unintentional risky) behaviour.

$>$ Lower level of skills: less opportunity for training and less experience on the tasks is an additional factor for erroneous behaviour, whereas lower skills also influence the quality of conscious decision making against risk.

New technologies and management approaches - tools have a similar effect, since they add to motives for high productivity standards and stress (due to higher speed and complexity). Modern equipment, new tasks and increase in the overall complexity have decreased workers' level of control on the process, since their depth of knowledge is eventually limited. Ambiguity in task definition, unclear relationships and the existence of stranger on unqualified workers may lead to errors of omission in decision making or inconsistent sets of decisions (Kochan et al. 1994; Mayhew, Quinlan and Ferris, 1997).

Unit size is also an important factor. Span of control in such units is smaller, which increases the intensity of control and subsequently the motivation for increased productivity. On the other hand, insecurity of work prospects is also high (due to the vulnerability of small companies or units) whereas skills are expected to be lower (less opportunities for training). These features only add stress and pressure to risky behaviour to the already low level of prevention in such units (that employ the majority of workforce). The influence of workers on their own work practices appears to be higher in small companies (Sorensen, Hasle and Bach 2007). 
New categories of employees (ageing, females, immigrants) have features that were not included in the existing model that was mainly based on culturally even, males of relatively young age. Insecurity and stress (mainly due to their special features) are the main OHS related implications. Their conscious decisions may also be influenced by their need to converge to the average workforce, different cognitive or physical features, culture, etc.

Labour mobility and high staff turnover has a direct impact on the acquired skills and training. Moreover, it affects motives pressing for productivity and increasing stress, due to insecurity of work prospects. This insecurity is also enhanced by lack of unionisation, which also results to less information for OHS. Thus the person is individualised in modern work environments, i.e. more likely to behave as an independent unit, which generally reduces job security and increases pressure for high productivity standards that may lead to risky behaviour and stress.

Reduction in government intervention and deregulation also add to this insecurity and individualism. Changing working patterns as well as a feeling of mistrust of government especially in issues such as pensions, shifts responsibilities from organisations to individuals (James, 2000). Mayhew, Quinlan and Ferris (1997) describe the situation in Australia: "Primarily because government action over OHS was focused merely on the hazards and risks, and not the economic driven labour intensification, inspectorate attempts to improve OHS were seen to be irrelevant, Futile, or even laughable".

Traditionally, the study of workplace accident risk has been developed through different scientific disciplines along three dimensions of research:

Accident models. Mainly based on systems study, a number of models describe causal mechanisms that lead to an accident. This dimension of research started with "sequential" models and gradually evolved with "epidemiological" and "systemic models" as workplace complexity increased.

$>$ Human error/ reliability. Variability of human performance is examined as the main cause of accidents.

$>$ Risk perception/communication. This point of view examines human perception of risk, the consequent behaviour and its relation to accidents.

The dimensions of human factors (human error and risk perception) started with behavioural and cognitive approaches to gradually evolve to socio-technical approaches in order to adapt to increasing workplace system integration during 70's and 80's, as the social component was becoming dominant, since both the size of the operational unit and the prospects of remaining in it were increasing. 
For example, safety culture, although facing a lot of criticism for its clarity, evolved to a key topic for safety. However, in the light of the new work environment some issues arise for its applicability:

$>$ Culture is relatively stable in time (Guldenmund, 2000). However, the recipe for success in today's business environment is continuous change, which does not allow for stable long-term features, such as culture. This limitation in time horizon is even more severe for SE's and for precarious employment, where short time horizon concerns employment itself for a large proportion of the workers in the organisation.

$>$ Some authors (Williamson and Weyman, 2005; Gadd and Collins, 2002; Richter and Koch, 2004) have raised concerns about the boundaries and interfaces of safety culture. In "lean" organisations, workers of autonomous units that are tightly coupled with collaborating units of other firms might feel closer to subcontractors than to the organisation itself. This context creates even more uncertainty to the definition of boundaries of safety culture, especially when the time horizon of this coexistence (employment) is narrowing.

$>$ Safety culture is considered to be a subset of (or at least affected by) national culture (Cooper, 2000). However, cross-national staff mobility brings together people of different national cultures and background in the same workplace, which questions the potential for the development of an enterprise safety culture, especially when the duration of this coexistence is narrow.

In general, new trends in work environment during the 90's have rapidly changed this context towards decentralisation and individualisation, making individual-level study (behavioural and cognitive) more relevant again. "In a foresighted prevention policy, individuals are not regarded as endangered persons who need protection, but rather as people who can act for themselves" (Bullinger, 2000).

All the dimensions of risk research can contribute to the completeness of the assessment of workplace risk, which is the basic tool for its management, especially in the modern work environment. Intentional behaviour (i.e. concessions) of workers against risk has to be seriously taken into account. Literature on risk perception can be very useful in this respect. Unintentional individual impact (human error) is also an important factor. Stress and cognitive limitations, along with complexity, are important factors for erroneous behaviour. The literature on human error can be very helpful for the incorporation of this parameter.

The incorporation of human factors and system complexity can be obtained through a combinational and multilateral conceptual model for workplace accidents. 
Figure 2: Conceptual model for multidimensional risk assessment

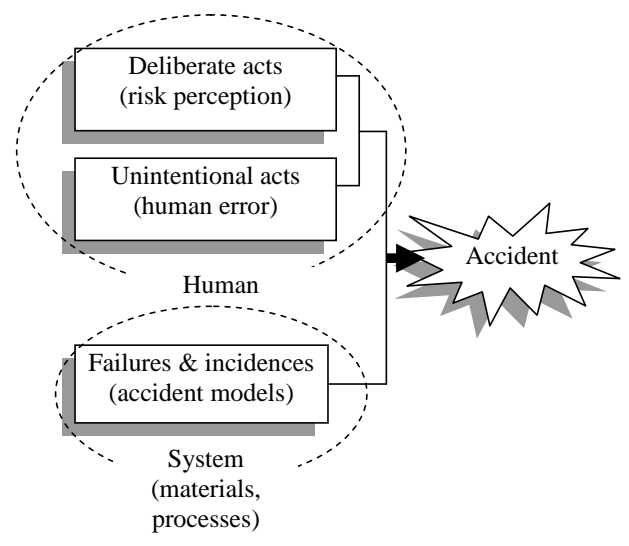

Accident is considered as a result of human acts and non human-related factors (e.g. materials, processes, etc.) acting in conjunction. In more detail, human acts are further analyzed in deliberate and unintentional acts (deliberate acts differ from "errors of commission" since they involve structured intent). Of course, this scheme is not a fault tree. The categories are not independent, since they affect each other. In other words they could not be applied as a threedimensional Cartesian system where each accident could be identified. A triangle scheme appears to be more proper.

Figure 3: Triangle scheme for taxonomy dimensions

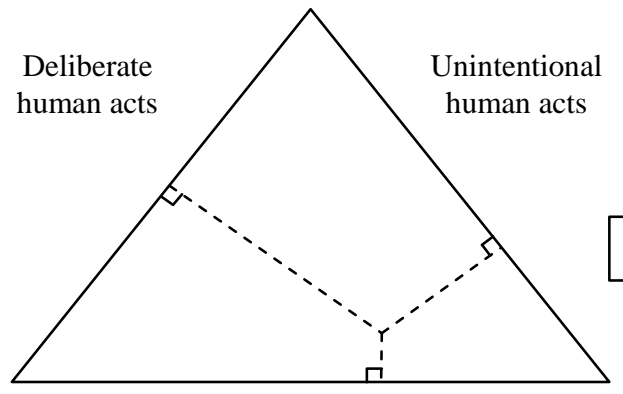

System (materials, processes)

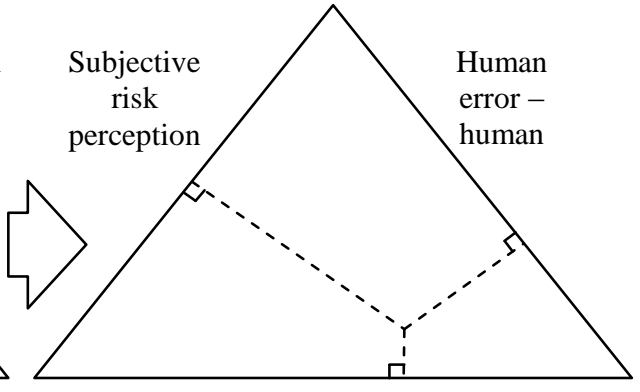

Accident models

For every point in this conceptual diagram, which represents a certain set of workplace conditions, there should be an optimum combination of conceptual models from each dimension given the requirements for sufficient description and maximum simplicity. Of course, models are not quantified entities to be 
objectively classified in a continuum. This taxonomy has a degree of subjectivity, which makes it a guide rather than a strict criterion for the selection of a model.

However, in the usual modern workplace, limitation of resources (especially in SE's and autonomous units) is a major problem. Usually, only a safety engineer is available, with limited time and theoretical knowledge to model workplace and to identify its risks. Therefore, the demand for effectiveness of modelling is almost as important as the demand for simplicity of the approach. An inefficient risk assessment is barely better than none, whereas a complex risk assessment might never be efficiently performed.

In other words, a busy safety engineer has neither the time to study theoretical models nor the capacity to select the proper one and apply it in every case. Therefore, a simple approach has to be developed in order to assist the whole process. Since the needs for multidimensionality and simplicity are equally important, this compromise can only take place at the expense of scientific precision and theoretical accuracy.

It is proposed that risk perception and human error are explicitly taken into account, however not in their theoretical context, but through simplified guidelines that will provide some insight without adding too much effort in the process of risk assessment. Therefore, existing models of each dimension of research have to be merged into fewer categories and to be simplified into certain guidelines (without their theoretical background). On the other hand certain simple criteria have to be set to assist the selection of the proper set of these guidelines in each case.

As described earlier in this paragraph, behavioural and cognitive models are becoming more relevant in the modern work environment due to increase of individualisation. Fortunately, these models are also the most simple to conceive and easier to standardise for someone with an engineering background.

This proposed approach will lead to a methodology without a solid theoretical basis, however with a potential to be easily applied by safety engineers during the process of risk assessment. Since this methodology aims mostly at the stage of risk identification, this theoretical deficit cannot be dangerously misleading, as any potential extra risks identified will be corrected in the stage of risk assessment. If any risks are not identified with this approach, they would not have been identified anyway without it.

\section{CONCLUSIONS}

Modern work environment has changed under the impact of globalisation of competition. Its main features affecting OHS are new technologies in methods and equipment, changes in the size of operational units and precarious or 
insecure employment. The main implications for occupational risk involve greater complexity in the workplace, greater potential for risky behaviour and more drivers of unconscious undesired behaviour (stress, complexity, etc.)

Therefore, the significance of the role of the human factors in modern work environment has increased so that they have to be explicitly taken into account, even in SE's; ignoring them would lead to inefficient assessment of risks. A new multilateral approach for modelling workplace and assessing its risks is required, which will take human factors into account, however without overloading the task of risk assessment, since the amount of resources assigned to this task and the usual existing knowledge are rather limited.

This paper proposes a general framework for the development of a multilateral approach that will combine accident models, risk perception models and human error models in order to better identify and assess workplace risk. This approach involves a procedure for the selection of the proper set of models of each aspect and the application of these models in the certain workplace.

Of course, given the limitations of resources for risk assessment, this approach has to be further simplified at the cost of its theoretical accuracy. It is proposed to group and simplify models into certain sets of practical guidelines and impose a simple context for the selection of the proper set depending on the characteristics of the workplace

\section{REFERENCES}

Biggins, R. (1996): "Summary of RoSPA's Proposals for Promoting Health and Safety in Small Firms". In: Abstracts from the Workshop on Occupational Health Strategies, European Foundation for the Improvement of Living and Working Conditions.

http://www.eurofound.europa.eu/pubdocs/1997/49/en/1/wp9749en.pdf (10.04.09)

Bullinger, H.-J. (2000): "The changing world of work: prospects and challenges for health and safety". In: OSHA. 2000. Magazine 2: The changing world of work. Luxembourg: Office for Official Publications of the European Communities. Available

http://osha.europa.eu/publications/magazine/2/magazine2_en.pdf/at_download/ file

Clifton, R. (2000): "The consequences of new enterprise structures. In: OSHA. 2000. Magazine 2: The changing world of work". Luxembourg: Office for Official Publications of the European Communities. http://osha.europa.eu/publications/magazine/2/magazine2_en.pdf/at_download/ file (10.04.09) 
Dooley, J. J. (1998): “Unintended Consequences: Energy R\&D in a Deregulated Energy Market”, Energy Policy. 26(7): 547-555.

Dorman, P. (2000) "The Economics of Safety, Health and Well-Being at Work: An Overview". InFocus Program on SafeWork, International Labour Organisation, The Evergreen State College. http://www.ilo.org/public/english/protection/safework/papers/ecoanal/ecoview.pd $f(10.04 .09)$

Duffield, J. S. (1999): "Foreword to International Trends in Major Accidents and Activities by the European Commission Towards Accident Prevention", Journal of Loss Prevention, 12(1). 1.

Etienne, P. (1996): "Inspection and Control Policies". In: Abstracts from the Workshop on Occupational Health Strategies, European Foundation for the Improvement of Living and Working Conditions. http://www.eurofound.europa.eu/pubdocs/1997/49/en/1/wp9749en.pdf (10.04.09)

European Network for SME Research, (2004): "Observatory of European SME's: SME's in Europe 2003".Luxembourg: Office for Official Publications of the European Communities. http://ec.europa.eu/enterprise/enterprise_policy/analysis/doc/smes_observatory _2003_report7_en.pdf (10.04.09)

Eurostat, (2008): "Population and Social Conditions: Labour Market". http://ec.europa.eu/eurostat/ (10/04.09)

Guadalupe, M. (2003): "The Hidden Costs of Fixed Term Contracts: The Impact on Work Accidents", Labour Economics, 10: 339-357.

Hämäläinen, P., Takala, J., Saarela, K. L. (2006): "Global Estimates of Occupational Accidents", Safety Science, 44: 137-156.

Harrisson, D., Legendre, C. (2003): "Technological Innovations, Organizational Change and Workplace Accident Prevention", Safety Science 41: 319-338

James, L. (2000): "Redefining work as a result of globalisation and the use of new information technologies". In: OSHA. 2000. Magazine 2: The changing world of work. Luxembourg: Office for Official Publications of the European Communities.

http://osha.europa.eu/publications/magazine/2/magazine2_en.pdf/at_download/ file (10.04.09)

Johansson, A. (2000): "Work organisation in an ageing Europe". In: OSHA. (2000): "Magazine 2: The changing world of work". Luxembourg: Office for Official Publications of the European Communities. 
http://osha.europa.eu/publications/magazine/2/magazine2_en.pdf/at_download/ file (10.04.09)

Kochan, T., Smith, M., Wells, J., Rebitzer, J. (1994): "Human Resource Strategies ant Contingent Workers: The Case of Safety in the Petrochemical Industry". Cited in: Mayhew C., Quinlan M., Ferris R. 1997. The Effects of Subcontracting/Outsourcing on Occupational Health and Safety: Survey Evidence from Four Australian Industries. Safety Science, 1-3: 163-178

Launis, K., Pihlaja, J. (2007): "Changes in production concepts emphasize problems in work-related well-being", Safety Science, 45: 603-619

Leveson, N., (2004): "A New Accident Model for Engineering Safer Systems", Safety Science, 42: 237 - 270.

Lopez - Varcarel, A. (2002): "New Challenges and Opportunities for Occupational Safety and Health $(\mathrm{OSH})$ in a Globalized World", International Labour Office, http://www.ilo.org/public/english/protection/safework/econo/globchal.htm (10.04.09)

Mayhew, C., Quinlan, M., Ferris, R. (1997): "The Effects of Subcontracting/Outsourcing on Occupational Health and Safety: Survey Evidence from Four Australian Industries", Safety Science, 1-3: 163-178

OECD, (1989): "Occupational Accidents in OECD Countries", www.oecd.org/dataoecd/63/54/3888265.pdf (10.04.09).

OSHA, (2002a): "FACTS 25. New Forms of Contractual Relationships and the Implications for Occupational Safety and Health. Summary of a Agency report". Luxembourg: Office for Official Publications of the European Communities. http://osha.europa.eu/publications/factsheets/25 (10.4.09)

OSHA, (2002b): "FORUM 5. The Changing World of Work. Trends and Implications for Occupational Safety and Health in the European Union". Luxembourg: Office for Official Publications of the European Communities. http://osha.europa.eu/publications/forum/5/forum5_en.pdf/at_download/file (10.4.09)

OSHA, (2002c): "FORUM 7. Prevention of Work-related Accidents: a different strategy in a changing world of work?" European Conference and Closing Event of the European Week for Safety and Health at Work 2001. Luxembourg: Office for Official Publications of the European Communities. http://osha.europa.eu/publications/forum/7/forum7_en.pdf/at_download/file (10.4.09) 
OSHA, (2002d): "New trends in accident prevention due to the changing world of work. Luxembourg: Office for Official Publications of the European Communities".

http://osha.europa.eu/publications/reports/208/newtrends_en.pdf/at_download/fi le (10.4.09)

Rasmussen, J. (1988): "International Workshops to Develop a Multi-Disciplinary Research Program Based on a Holistic System Approach to Safety and Management of Risk in Large-Scale Technological Operations". Cited in: Bellamy, J. and Geyer T.A.W. (ed J. C. Williams) (1992): Organisational, Management and Human Factors in Quantified Risk Assessment. HSE Contract $\begin{array}{lll}\text { Research } & \text { Report. } & \text { No. }\end{array}$ www.hse.gov.uk/research/crr_pdf/1992/crr92034.pdf (10.4.09)

Salminen, S. (2004): "Have Young Workers More Injuries than Older Ones? An International Literature Review", Journal of Safety Research, 35, 513-521.

Sauter, S. and Rosenstock, L. (2000): An American Perspective. In: OSHA, (2000): "Magazine 2: The changing world of work. Luxembourg: Office for Official Publications of the European Communities". http://osha.europa.eu/publications/magazine/2/magazine2_en.pdf/at_download/ file (10.4.09)

Sorensen, O.H., Hasle, P. and Bach, E. (2007): "Working in small enterprises Is there a special risk?", Safety Science, 45: 1044-1059 